http://ejtr.vumk.eu

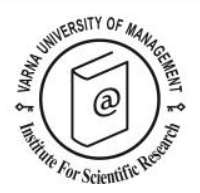

\title{
A Game Theory approach to Airbnb and hotels competition
}

\author{
Juan Pedro Aznar ${ }^{1 *}$, Josep Maria Sayeras Maspera ${ }^{2}$ and Xavier Quer ${ }^{3}$
}

Received: 31/07/2018 Accepted: 07/09/2018

\begin{abstract}
${ }^{I}$ Associate Professor. Economics, Finance and Accounting Department, ESADE Business and Law School, Ramon LLull Univeristy. Barcelona, Spain. E-mail: juanpedro.aznar@esade.edu

Avenida Pedralbes, 60-62, Barcelona, 08034, Phone number: + 34932806162 (2231 extension)

${ }^{2}$ Associate Professor. Economics, Finance and Accounting Department. ESADE Business and Law School, Ramon LLull Univeristy. Barcelona, Spain. E-mail: josepm.sayeras@esade.edu

Avenida Pedralbes, 60-62, Barcelona, 08034

${ }^{3}$ Research Assistant. Economics, Finance and Accounting Department. ESADE Business and Law School, Ramon LLull Univeristy. Barcelona, Spain. E-mail: xavier.quer@alumni.esade.edu

Avenida Pedralbes, 60-62, Barcelona, 08034

* Corresponding author
\end{abstract}

\section{Abstract}

The rapid growth of Airbnb listings has represented a challenge for hotels. While most of the existent literature has focused on empirically measuring the impact of Airbnb listings on hotels' revenues and profitability, the present research is one of the first attempts to develop a theoretical framework based on game theory to model a hotel's best response in terms of investment to improve the quality of service and pricing strategy. The model results suggest that hotel location, the average value of long-term rental contracts and the density of available apartments influence the hotel strategy.

(C) 2019 Varna University of Management. All rights reserved

Keywords: Airbnb, pricing strategy, quality, sequential game.

Citation: Aznar, J., J. Maspera and X. Quer (2019) A Game Theory approach to Airbnb and hotels competition. European Journal of Tourism Research 21, pp. 119-123

\section{Introduction}

Airbnb has changed the market structure in the accommodation industry in less than a decade; according to the information provided by an online platform, in 2017, Airbnb was present in 191 countries with more than 4 million listings available. Most cities in which tourism is a relevant economic activity have experienced an exponential growth in the number of listings; considering the period 2009 to 2016, Paris listings increased from 47 to 36000 , Dublin listings increased from 2 to 2200, and Barcelona listings increased from 4 to 9200 (data retrieved from AIRDNA website). This change in the market structure represents a challenge for hotel managers and other stakeholders. Policy makers and scholars are trying to answer some crucial questions about the impact of Airbnb in our cities in order to establish the right regulations, with the impact of Airbnb on housing prices, rents and the externalities associated with a high density of 
tourism in a concrete area of the city being particularly important (Lee, 2016; Quattrone et al., 2016).

One of the first questions that the academic literature has tried to answer is how Airbnb is affecting the economic and financial performance of hotels. According to empirical research on the lodging industry in Texas, a $1 \%$ increase in the number of Airbnb listings will result in a $0.05 \%$ drop in revenues (Zervas et al., 2017). The impact differs according to hotel category. Hotels in the upper luxury segment are less affected; this result suggests that hotels can react to this new form of competition by increasing their investment in providing higher quality services, differentiating themselves from apartments by offering a more value-added product. Empirical evidence suggests that in most touristic European cities, the supply structure has changed towards upscale hotels in terms of star rating. According to the information provided by the official statistical services of several European cities, in Amsterdam, the proportion of beds supplied that correspond to 1 and 2 star hotels has decreased from $22.96 \%$ (2009) to $17.7 \%$ (2015), whereas 4 and 5 star hotels are supplying $51.32 \%$ of the beds, compared to the 2009 figure of $46.61 \%$ (Geemeente Amsterdam, 2017). In Milan, the proportion of beds supplied by 4 and 5 star hotels has increased from $55.75 \%$ to $63.16 \%$ (2009-2015) (Comune de Milano Area Turismo, 2017).

Academic literature has not yet developed a theoretical framework that aims to understand hotels' response to the new competitors represented by the Airbnb online platform. Game Theory has been widely used in trying to model how strategic decisions are taken in the hospitality industry (Zhang et al., 2009; Sheng, 2011; Yang, 2009), particularly sequential games are a frequent tool of modelling industries like the hotel industry, in which price strategy is set up after location and investment (Wei and Ma, 2012; Huang et al., 2010). This research presents a sequential game in which hotels and apartment landlords try to maximize profits. The objective of the model is to understand how investment in quality and price strategy for hotels will change after the disruption of Airbnb competition and identify the key determinants of the optimum hotel strategy.

\section{The model}

The model is a sequential game in which a hotel with a given location faces new competition from apartments. The hotel can choose to invest in improving the quality of the service provided, and in a second stage, the hotel and the apartments renting to tourist simultaneously establish their prices. The utility function for consumers and the specification of the quality investment cost are taken from Sanjo's model (Sanjo, 2007).

Suppose a city with a length of L; one extreme of the segment contains the centre of the city, the most desirable location for tourist lodging. The city has $\mathrm{M}$ available apartments; for simplicity, we suppose that each apartment is located at a distance L/M from each other. The first apartment is located at the centre of the city; therefore, the last apartment is located at a distance $(\mathrm{M}-1) \times \mathrm{L} / \mathrm{M}$. Each landlord has to decide whether to rent the apartment to residents in the form of long-term contracts or to offer it to tourists in the form of short-term contracts through Airbnb. Assuming that $c$ represents the value per day for a long-term contract with residents; a landlord will offer the apartment to tourists on short-term contracts if the expected price from renting to tourists is above $c$.

In terms of the utility function for tourists, the specification for the function is based on Sanjo's paper (Sanjo, 2007).

$$
U_{j}^{i}=R-P_{j}+q_{j}-t x_{j}
$$

The utility that a tourist $i$ obtains from staying at $j$, in either an apartment or a hotel, is given by the reserve value $(R)$, which is negatively affected by the price $\left(P_{j}\right)$, positively affected for the level of the quality of the service $\left(q_{j}\right)$ and negatively affected by the distance from the accommodation unit, apartment or hotel room, to the city centre. The parameter $t$ measures the disutility associated with one additional unit of distance to the centre. All tourists have an identical utility function. 
The hotel is located at a distance $X_{H}$ from the centre, and the cost of quality is given by $C\left(q_{H}\right)=\frac{1}{2} \theta q_{H}^{2}$, following Sanjo's formulation (Sanjo, 2007). In the first stage, the hotel determines the investment in quality; in the second stage the hotel and the apartments determine price simultaneously. This model assumes that apartments differ only in their location and cannot invest in quality. Some empirical research on Airbnb suggests that the most important factor affecting the price a landlord can charge is the distance from the places tourists want to visit (Wang and Nicolau, 2017), an effect captured by this model specification. This sequential model can be solved by applying backward induction.

We assume that the supply of accommodation in all forms is higher than the demand; there are $N$ tourists visiting the city each day. Airbnb apartments will choose the maximum price provided they can attract a tourist. Each apartment will attract a tourist if the utility associated with staying at the hotel is at least equal to that offered by other apartments and the hotel. Apartment 1, located at the centre, can charge a higher price but needs to provide a higher utility than the hotel; the price $\left(P_{1}\right)$ must meet the following condition:

$$
P_{1} \leq P_{H}+t x_{H}-q_{H}
$$

The second apartment, located at a distance $\mathrm{L} / \mathrm{M}$ form the city centre, needs to apply a discount of $t \times \mathrm{L} / \mathrm{M}$ compared with the apartment at the centre to compensate for the disutility associated with being further from the centre. Applying the same discount for the following apartments until the return equals that from offer long-term contracts to residents, the number of apartments available at Airbnb will be $(n)$ :

$$
n=\left[P_{H}+t X_{H}-q_{H}-c\right] \frac{M}{t L}+1
$$

The hotel demand function is equal to the number of tourists minus the number of tourists staying at apartments $(N-n)$. The hotel has to determine the price $\left(P_{H}\right)$ and the investment in quality $\left(q_{H}\right)$; the expression for the economic profits is:

$$
\pi=[N-n) P_{H}-\frac{1}{2} \theta q_{H}^{2}
$$

Considering the expression for $\mathrm{n}$ given by equation 3, the function that must be maximized by the hotel manager is:

$\pi=\left[N-\left(P_{H}+t X_{H}-q_{H}-c\right) \frac{M}{t L}\right] P_{H}-\frac{1}{2} \theta q_{H}^{2}$

To solve the model, the first derivative with respect to price equals 0 ; determining an expression for the price that is substituted in the hotel profit condition allows us to apply optimization conditions for the investment in quality, obtaining as a final result the optimum values for the investment in quality and the hotel price. These results are expressed in their final form by equations 6 and 7, respectively.

$$
\begin{aligned}
& q_{H}=\frac{M}{2 t L \theta-M}\left[c-t x_{H}+(N-1) \frac{t L}{M}\right] \\
& P_{H}=\frac{t L \theta}{2 t L \theta-M}\left[c-t X_{H}+(N-1) \frac{t L}{M}\right]
\end{aligned}
$$

\section{Results}

Some of the theoretical results of this model are consistent with the available empirical evidence and provide a guide for hotel managers and policy makers interested in the social effects that this new form of activity is generating in many cities around the world. One important conclusion of the model is the role of the factor $\frac{t L}{M}$, the apartment density in the city $M / L$. A higher apartment density implies a lower investment in quality; therefore, too many apartments act as a negative incentive for investing in quality, hence reducing the value added to hotels with a likely negative impact on the hospitality industry and employment. Cities with a high standard of living and higher prices for long-term contracts to residents, as measured by the parameter c, benefit from higher hotel prices and more investment in quality.

From the hotel managers' point of view, the model provides a clear insight in how important is to be located where tourist value most to be, hotels located in the best spots can apply higher prices, even in a market characterized by Airbnb apartments competition, and the higher profits allow for higher investment in quality. This higher investment in quality has 
also some spill over effects in industry wages and economic growth (Kadiyali and Kosova, 2013).

The model also provides some interesting outcomes for the policy makers, especially at local government level. Due to the disutility associated to distance, apartments tend to concentrate as near as possible to the touristic spots in the city, generating some negative effects like gentrification (Lee, 2016; Waschmuth and Weisler, 2017). The model suggests that some public polices, like investing in an efficient public transport system can reduce the disutility associated to the distance and therefore have a positive impact in a less geographically concentrated distribution of apartments. Finally, the average cost of renting an apartment in a long-term perspective for a resident, clearly correlated with higher GDP per capita and higher median incomes have according to this model three different effects: a lower number of apartments, a higher investment made by the hotel industry and higher hotel prices, ceteris paribus, affecting hotel profitability.

This model will benefit from further development in future research. Some aspects to consider are the inclusion of more than one hotel, combining an oligopoly structure for the hotel market with the apartments listed at Airbnb, or to consider long-term contract rent as an endogenous variable affected by apartment price. Finally, in terms of policy makers, defining a welfare function for residents and the analysis of the effects the new market generates on resident welfare is an important issue to consider in future research.

\section{Appendix: Mathematical development of the model}

Given that the utility function for consumer $i$ that gets accommodation from supplier $j$

$$
U_{j}^{i}=R-P_{j}+q_{j}-t x_{j}
$$

The hotel can invest in quality and we are assuming that apartments cannot invest in quality, they have a fixed location. The first apartment is located at a distance o from the centre, and each consecutive apartment at a distance L/M.
The price fixed for the apartment $1\left(P_{1}\right)$ in order to be at least as attractive to the consumer as the hotel is

$$
P_{1} \leq P_{H}+t x_{H}-q_{H}
$$

If we consider the rest of the apartment, they need to apply a discount compared with the apartment 1 because the disutility caused by their distance to the centre. Therefore:

$$
P_{2} \leq P_{1}-t \frac{L}{M}=P_{H}+t x_{H}-q_{H}-t \frac{L}{M}
$$

The landlords will offer apartments up to the point where renting to residents through longterm contracts, getting $c$, is equally profitable than lending to apartments.

$$
P_{n}=P_{H}+t x_{H}-q_{H}-t \frac{L(n-1)}{M}=c
$$

According to this last expression, the number of apartments can be written as:

$$
n=\left[P_{H}+t X_{H}-q_{H}-c\right] \frac{M}{t L}+1
$$

Considering $N$ tourist, there $\mathrm{n}$ staying at apartments so the demand for the hotel is $(N$ $n)$, the hotel has two decision variables, the hotel price $\left(P_{H}\right)$ and the investment in quality $\left(q_{H}\right)$. In a first stage the hotel decides the investment in quality in a second stage the hotel decides the price simultaneously with the apartments. The profits function for the hotel can be expressed as:

$$
\pi=[N-n) P_{H}-\frac{1}{2} \theta q_{H}^{2}
$$

Considering the previous value for $n$ and making the appropriate substitution in the profit function:

$$
\pi=\left[N-\left(P_{H}+t x_{H}-q_{H}-c\right) \frac{M}{t L}-1\right] P_{H}-\frac{1}{2} \theta q_{H}^{2}
$$

By applying backward induction taking the first derivative of the profits with respect to the price and making it equal to 0 , the following expression for the price as a function of the quality is found: 


$$
P_{H}=\frac{1}{2}\left[(N-1) \frac{t L}{M}-t x_{H}+q_{H}+c\right]
$$

The decision of the optimum level of investment is made maximizing the profit function with respect to the investment quality, including the price and quality relation from the last equation, so the profit expression is:

$$
\begin{array}{r}
\pi=\left[(N-1) \frac{2 M-t L}{2 M}+\frac{M}{2 t L}\left(q_{H}+c-t x_{H}\right)\right] \frac{1}{2} \\
{\left[(N-1) \frac{t L}{M}-t x_{H}+q_{H}+c\right]-\frac{1}{2} \theta q_{H}^{2}}
\end{array}
$$

Applying $\frac{\partial \pi}{\partial q_{H}}=0$ the level of investment that maximizes hotel's profit is

$$
q_{H}=\frac{M}{2 t L \theta-M}\left[c-t x_{H}+(N-1) \frac{t L}{M}\right]
$$

Applying the second derivative the quality investment from the last expression is a maximum if $2 t L \theta-M \geq 0$

The final expression for the price is:

$$
P_{H}=\frac{t L \theta}{2 t L \theta-M}\left[c-t x_{H}+(N-1) \frac{t L}{M}\right]
$$

\section{References}

AIRDNA website. https://www.airdna.co/market -data/app/es (Accessed on May 2018)

Comune di Milano Area Turismo (2017). Milano Tourism Statistics, http://sisi.comune. milano.it/ (Accessed in May 2018)

Gemmeente Amsterdam (2017). Amsterdam Yearbook 2016. URL: https://www.ois. amsterdam.nl/pdf/2016_jaarboek hoofdstuk_08.pdf_(Accessed in May 2018)

Huang, G. Q., Song, H., \& Zhang, X. (2010). A comparative analysis of quantity and price competitions in tourism supply chain networks for package holidays. The Service Industries Journal, 30(10), 15931606.

Kadiyali, V., \& Kosová, R. (2013). Inter-industry employment spillovers from tourism inflows. Regional Science and Urban Economics, 43(2), 272-281.

Lee, D. (2016). How Airbnb short-term rentals exacerbate Los Angeles's affordable housing crisis: Analysis and policy recommendations. Harvard Law \& Policy Review, 10, 229-253.

Quattrone, G., Proserpio, D., Quercia, D., Capra, L., \& Musolesi, M. (2016, April). Who benefits from the sharing economy of Airbnb? In Proceedings of the 25th international conference on world wide web (pp. 1385-1394). International World Wide Web Conferences Steering Committee.

Sanjo, Y. (2007). Hotelling's location model with quality choice in mixed duopoly. Economics Bulletin, 18(2), 1-11.

Sheng, L. (2011). Regional competition and sustainable development: a game theory model for tourism destinations. European Planning Studies, 19(4), 669-681.

Wang, D., \& Nicolau, J. L. (2017). Price determinants of sharing economy based accommodation rental: A study of listings from 33 cities on Airbnb. com. International Journal of Hospitality Management, 62, 120-131.

Wachsmuth, D., \& Weisler, A. (2017). Airbnb and the rent gap: Gentrification through the sharing economy. Environment and Planning A: Economy and Space, $0308518 \times 18778038$.

Wei, X., Qu, H., \& Ma, E. (2012). Decisive mechanism of organizational citizenship behavior in the hotel industry-an application of economic game theory. International Journal of Hospitality Management, 31(4), 1244-1253.

Yang, S., Huang, G. Q., Song, H., \& Liang, L. (2009). Game-theoretic approach to competition dynamics in tourism supply chains. Journal of Travel Research, 47(4), 425-439.

Zervas, G., Proserpio, D., \& Byers, J. W. (2017). The rise of the sharing economy: Estimating the impact of Airbnb on the hotel industry. Journal of Marketing Research, 54(5), 687-705.

Zhang, H. Q., Heung, V. C., \& Yan, Y. Q. (2009). Play or not to play-An analysis of the mechanism of the zero-commission Chinese outbound tours through a game theory approach. Tourism Management, 30(3), 366-371. 